\title{
Pelaksanaan Ekstrakulikuler Sepak Bola sebagai Ekstrakulikuler Unggulan di SMP Muhammadiyah 7 Surakarta
}

\author{
Maulida Mina1), Rispratama ${ }^{2)}$, Bibit Waluyo ${ }^{3),}$ \\ 1)2)3)Universitas Muhammadiyah Surakarta \\ ${ }^{1)}$ Maulidaminna1606@gmail.com ${ }^{2)}$ rispratama2898@gmail.com \\ 3)bibitwaluyo2898@gmail.com \\ doi: 10.23917/blbs.v2i1.11614
}

\begin{abstract}
Abstrak. Penelitian ini bertujuan untuk mengetahui dan memahami proses latihan ekstrakurikuler sepak bola untuk menumbuhkan bakat siswa di SMP Muhammadiyah 7 Surakarta. Jenis penelitian yang digunakan adalah penelitian kualitatif dengan teknik observasi, dokumentasi dan wawancara. Observasi ini dilakukan pada siang hari ketika siswa sudah mulai melakukan ekstrakurikuler di lapangan. Selanjutnya penulis melakukan wawancara kepada Iqbal Hanif Eka Saputra salah satu siswa yang mengikuti ekstrakurikuler sepak bola di SMP Muhammadiyah 7 Surakarta. Validasi data yang ada dalam penulisan ini melalui trianggulasi sumber dan trianggulasi teknik. Hasil penelitian ini menunjukkan bahwa setelah melakukan kegiatan ekstrakurikuler sepak bola adalah terwujudnya siswa yang aktif dalam bidang olahraga khusunya sepak bola dan unggul dalam ranah keolahragaan.
\end{abstract}

Kata kunci : minat, prestasi, unggul

\section{PENDAHULUAN}

Program Pengenalan lapangan Persekolahan 1 (PLP 1) merupakan suatu kegiatan yang wajib dilaksanakan bagi mahasiswa FKIP dan FAI UMS untuk mendapatkan gelar sarjana. PLP 1 dilakukan dengan tujuan agar mahasiswa memiliki dasar pendidik dan memiliki kompetensi akademik kependidikan yang baik. Kegiatan ini dilaksanakan berdasarkan UU RI Nomor 20 Tahun 2003 tentang Sistem Pendidikan Nasional, UU RI Tahun 2005 tentang Guru dan Dosen, UU RI Nomor 12 Tahun 2012 tentang Pendidikan Tinggi, PP RI Nomor 19 Tahun 2005 tentang Standar Nasional Pendidikan, Peraturan Menteri Pendidikan dan Penerapan Kebudayaan RI Nomor 73 Tahun 2013 tentang Penerapan Pendidikan Kualifikasi Nasional Indonesia Bidang Pendidikan Tinggi, dll. Dengan adanya Program Pengenalan Lapangan Persekolahan 1 (PLP 1) diharapkan mahasiswa memiliki seperangkat pengetahuan, keterampilan, nilai dan sikap serta pola tingkah laku yang diperlukan sebagai calon guru professional.

Program Pengenalan Lapangan Persekolahan 1 (PLP 1) dilakukan secara observasi di SMP Muhammadiyah 7 Surakarta. 
Dwi sarjianto dan Sujarwandi (2011: 2), mengatakan bahwa sepak bola adalah olahraga terpopuler di jagad raya ini, hamper semua orang bisa memainkan olahraga yang mengandalkan kaki ini, untuk bisa mahir memainkan si kulit bundar diperlukan beberapa teknik dasar seperti menendang, mengoper, menggiring, dan menghentikan bola. Sepak Bola merupakan salah satu ekstrakurikuler yang diminati siswa di SMP Muhammadiyah 7 Surakarta guna mewadahi minat dan bakat siswa yang memiliki kelebihan dalam bidang olahraga, khususnya siswa yang mempunyai hobi atau kegemaran sepak bola, sehingga di ekstrakurikuler ini kedepannya siswa dapat bersaing dan menghadapi para pesaing di dunia yang semakin dinamis ini.

Ada beberapa penelitian yang dilakukan terkait dengan ekstrakurikuler sepak bola. Irsyad Faiz Ramadhan (2018) yang memaparkan hasil penelitian menunjukan bahwa Program Ekstrakurikuler Sepak Bola di SMP Negeri 2 Berbah cenderung dalam kategori rendah. Dapat dilihat melalui porsentase kategori sangat tinggi sebesar 0,7 \%, pada kategori tinggi 37,9\%, kategori rendah sebesar 47,1\% dan kategori sangat rendah sebesar 4,3\%. Penelitian Rizki Fauzi (2016) dengan judul Survei Pola Pembinaan Ekstrakurikuler Olahraga sepak Bola Sekolah di SMP Negeri di Kabupaten Kebumen, ia menemukan bahwa pembinan ekstrakurikuler olahraga sepak bola sudah cukup baik dilihat dari manusia, kerjasama, tujuan, peralatan, program latihan, fasilitas, target prestasi, pelatihaan, sekolah, siswa, dan orang tua di SMP N di Kabupaten Kebumen. Dan penelitian Noperto Pirman (2013) yang memaparkan hasil penelitian menunjukan bahwa minat siswa dalam mengikuti ekstrakurikuler sepak bola di SMP Negeri 5 Parindu Kabupaten Sanggau adalah sebesar $51,66 \%$ dengan tingkat persentase sebesar 89,07\% termasuk dalam kategori tinggi.

Dari kegiatan ini penulis sebagai pengamat menilai bahwa dengan adanya ekstrakurikuler sepak bola di SMP Muhammadiyah 7 Surakarta meningkatkan kreativitas siswa dan pola pikir di luar kelas menjadi cerdas dan kreatif. Apabila dalam kegiatan ekstrakurikuler ini dilaksanakan dengan baik dan konsisten sesuai tujuan awal, maka akan berhasil membentuk generasi siswa yang siap bersaing di ranah nasional melalui kemampuan skill olahraga sepak bola. Tujuan pengamatan terhadap program ekstrakurikuler sepak bola dari SMP Muhammadiyah 7 Surakarta diharapkan dapat menjadi motivasi dalam dunia pendidikan khususnya olahraga untuk 
mengembangkan bakat anak.

Adapun runusan masalah dari artikel ini yaitu bagaimana pelaksanaan ekstrakurikuler sepak bola sebagai ekstrakurikuler unggulan di SMP Muhammadiyah 7 Surakarta? Sedangkan tujuan dari artikel ini yaitu mendeskripsikan bagaimana pelaksanaan ekstrakurikuler sepak bola sebagai ekstrakurikuler unggulan di SMP Muhammadiyah 7 Surakarta.

\section{METODE PENELITIAN}

Metode yang digunakan dalam penelitian ini adalah metode pengamatan, dokumentasi dan wawancara. Subjek penelitian ini adalah siswa. Pengumpulan data-data untuk artikel ini dilakukan selama dua minggu pada tanggal 27 Januari 2020 - 11 Februari 2020 mengikuti PLP 1 di SMP Muhammadiyah 7 Surakarta. Pengamatan yang kami lakukan meliputi kegiatan yang ada di ekstrakurikuler sepak bola, kelebihan program ekstrakurikuler sepak bola dibanding ekstrakurikuler yang lain, serta dampak yang diberikan terhadap ekstrakurikuler tersebut. Untuk metode wawancara dilakukan dengan cara menanyakan beberapa hal yang berkaitan dengan minat siswa dan metode latihan yang digunakan. Sedangkan dokumentasi dan pengamatan dilakukan dengan secara langsung di dalam kegiatan ekstrakurikuler sepak bola tersebut.

\section{HASIL PENELITIAN DAN PEMBAHASAN}

Wawancara dilakukan kepada salah satu siswa yang mengikuti ekstrakurikuler sepak bola, yaitu kapan ekstrakurikuler dilaksanakan, berapa jumlah siswa yang mengikuti ekstrakurikuler sepak bola dan bagaimana system pengrekrutan siswa dalam ekstrakurikuler tersebut.

Siswa : "Latihane ki jam 2 sampe jam 4 sore mas, nek dino sabtu podo jam 2 sampe jam 4 tapi tergantung pelatih. Sing melu 22 orang, pas mlebune ekstrakurikuler ora enek ketentuane. Nek pas lomba kui enek seleksi ben iso melu pertandingan"

"Latihan ini jam 2 sampai jam 4 sore mas, kika hari sabtu sama jam 2 sampai jam 4 tapi tergantung pelatih. Yang mengikuti 22 orang, ketika masuk ekstrakurikuler tidak ada ketentuan. Namun jika lomba itu ada seleksi agar dapat ikut pertandingan."

Program ekstrakurikuler sepak bola dilakukan setiap 1 minggu sekali yaitu di hari kamis jam 14.00-16.00, sedangkan untuk dihari sabtu menyesuaikan jam kegiatan siswa ketika disekolah (jam 14.00-16.00). Jumlah siswa yang mengikuti

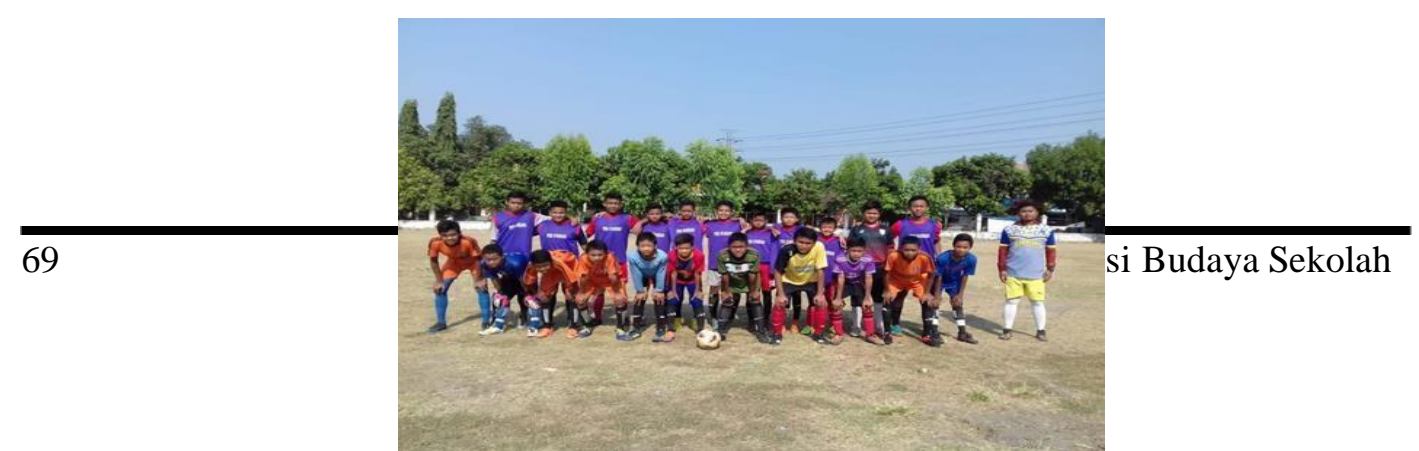


ekstrakurikuler sepak bola yaitu 22 anak. Untuk kriteria dapat mengikuti ekstrakurikuler sepak bola tidak ada. Hanya saja untuk menuju pertandingan ada beberapa hal yang perlu diseleksi dalam memilih.

Gambar 1. Siswa mengikuti ekstrakurikuler sepak bola

Observasi yang dilakukan yaitu Fasilitas yang terdapat dalam program ekstrakurikuler sepak bola yaitu adanya tempat berlatih (lapangan yang cukup memadai bagi siswa) dan sarana prasarana yang diberikan seperti bola sepak dan kun. Untuk pelatih sendiri, SMP Muhammadiyah 7 surakarta memiliki pelatih sepak bola yang memiliki latar belakang mantan pemain persis Solo. Melalui fasilitas yang diberikan, memiliki harapan agar siswa semakin semangat berlatih.

Kemudian menanyakan mengenai evaluasi yang dilaksanakan di SMP Muhammadiyah 7 Surakarta.

Siswa: "Breafing mesti ning akhir latihan karo nek enek event mesti enek evaluasi seko pelatih mas"

"Breafing pasti di akhir latihan dan jika ada event pasti ada evaluasi dari pelatih mas."

Evaluasi diadakan pada setiap adanya latihan rutin (disetiap minggunya) atau jika ada event/turnamen. Pelatih memberikan arahan dan motivasi kepada siswa agar semakin terarah dan semakin baik.

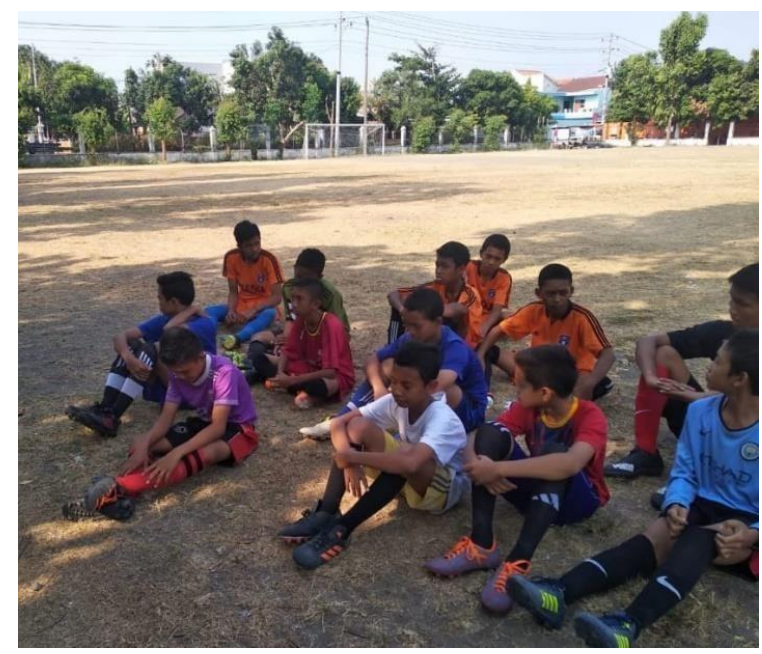

Gambar 2. Siswa diberikan evaluasi setelah latihan

Observasi yang dilakukan yaitu Ekstrakurikuler sepak bola memiliki metode latihan yaitu pemanasan/fisik, fun game, kemudian pendinginan. Melakukan pemanasan seperti lari, 
jogging, dan kombinasi sesuai kebutuhan siswa, dan disetiap 1 atau 2 minggu sekali diadakan fisik . yaitu melakukan pengkondisian tubuh siswa melalui fisik dari atas kepala sampai bawah kaki. Kemudian adanya fun game yang setiap minggunya diacak untuk membagi tiap- tiap kelompoknya. Agar para siswa dapat menumbuhkan rasa solidaritas dan kekompakan antar teman. Kemudian pendinginaan biasanya dilakukan stretching.

Kemudian menanyakan mengenai bagaimana target kedepannya, metode latihan ketika akan kejuaraan dan prestasi yang ada di ekstrakurikuler sepak bola di SMP Muhammadiyah 7 Surakarta.

Siswa: "Enek mas, mesti melu tanding karo kejuaraan. Latihane nek meh tanding luweh akeh dan ono latihan fisike. Mas nova kui pernah dadi kipper Persis Solo U-15"

"Ada mas, pasti ikut tanding kejuaraan. Latihan jika akan tanding lebih banyak dan ada latihan fisiknya. Mas Nova itu pernah jadi kipper Persis Solo U-15."

Program lain yang diterapkan pada ekstrakurikuler sepak bola yaitu target menuju pertandingan atau mengikuti kejuaraan. Setiap minggunya pasti ada target tersendiri untuk penyetabilan fisik para siswa. Namun jika ada pertandingan atau kejuaraan, mereka lebih banyak berlatih. Baik fisik maupun game. Kegiatan pertandingan yang pernah diikuti dari antar siswa sampai pertandingan luar kota. Salah satu siswa yang berkesempatan menjadi kipper di Persis Solo U-15 yaitu Nova Romadhona Saputra.

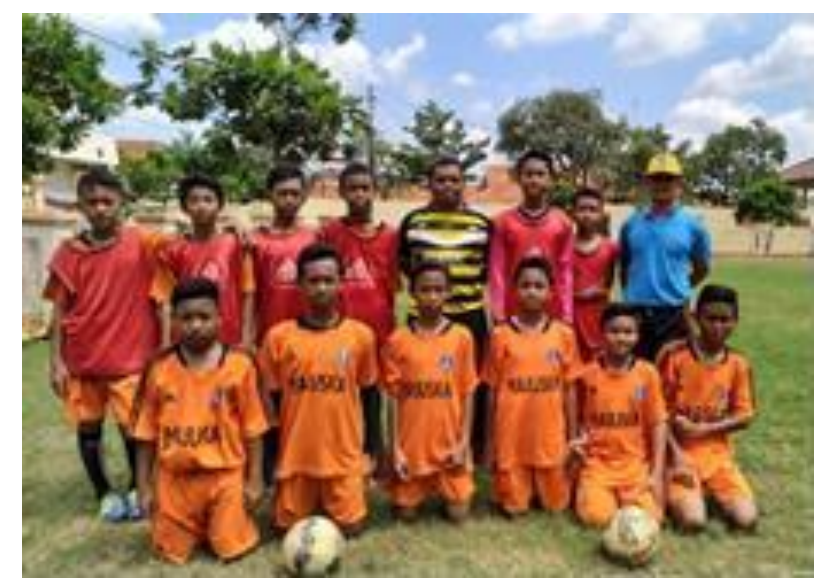

Gambar 3. Siswa mengikuti pertandingan antar siswa 


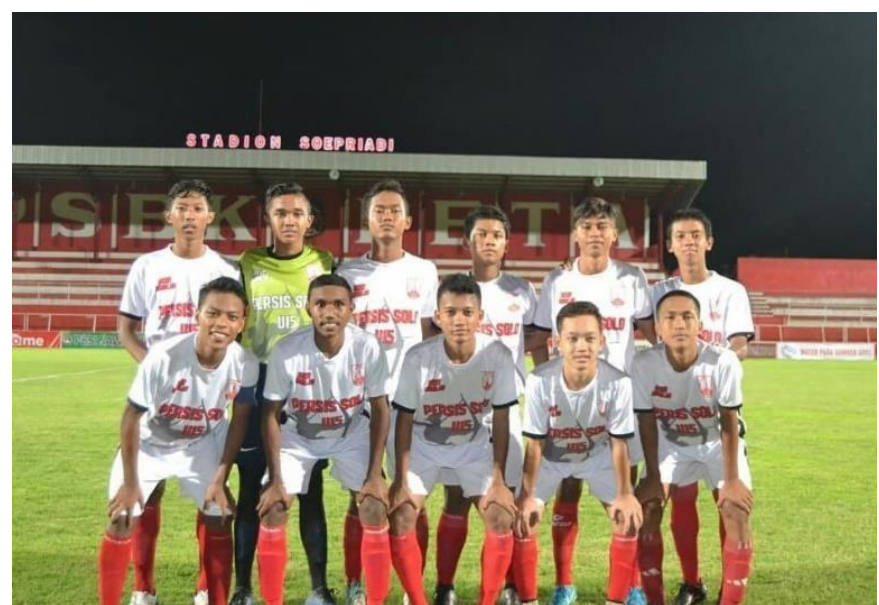

Gambar 4. Nova Romadhona Saputra ketika menjadi kipper di Persis Solo U-15

Hasil penelitian terdahulu, Irsyad Faiz Ramadhan (2018) mendapatkan hasil bahwa minat siswa dalam ekstrakurikuler sepak bola terbilang rendah. Sarana dan prasarana yang ada padahal sudah memadai namun minat dan keinginan siswa belum ada. Kehadiran siswa yang kurang konsisten. Sedangkan minat siswa pada ekstrakurikuker sepak bola di SMP Muhammadiyah 7 Surakarta terbilang tinggi. Karena siswa yang memiliki keinginan untuk datang dan sarana prasarana yang sudah memadai membuat siswa untuk lebih semangat. Rizki Fauzi (2016) mendapatkan hasil bahwa minat siswa dalam mengikuti ekstrakurikuler olahraga sepak bola sudah cukup baik dilihat dari manusia, kerjasama, tujuan, peralatan, program latihan, fasilitas, target prestasi, pelatih, sekolah, siswa, dan orang tua di SMP N di kabupaten Kebumen.

Di SMP tersebut sangat baik dalam menjalani estrakurikuler. Karena dari pihak siswa dan sarana prasarana sangat memadai. Sama dengan minat siswa dalam ekstrakurikuler di SMP Muhammadiyah 7 Surakarta, mereka sangat antusias dalam mengikuti ekstrakurikuler sepak bola ditinjau dari kehadiran dan prestasi yang dicapai. Noperto pirman (2013) mendapatkan hasil bahsa siswa di SMP Negeri 5 Parindu memiliki tingkat keinginan tinggi di ekstrakurikuler sepak bola. Karena ditinjau dari keinginan dan bakat siswa dalam mengikuti ekstrakurikuler sepak bola yang menjadi prestasi di SMP Negeri 5 Parindu. Sama halnya dengan SMP Muhammadiyah 7 Surakarta, yang memiliki prestasi di bidang olahraaga khususnya sepakbola. Dan lebih jelasnya juga memiliki prestasi yaitu ada salah satu siswa menjadi kipper di Persis Solo U15 . 


\section{SIMPULAN}

Berdasarkan hasil pengamatan dapat disimpulkan bahwa adanya program ekstrakurikuler sepak bola dapat membantu menyalurkan dan mengembangkan bakat siswa. Dengan program yang ada siswa dapat memperdalam dan lebih memiliki wawasan yang luas serta lebih baik dalam bidang olahraga khususnya pada cabang olahraga sepak bola.

\section{DAFTAR PUSTAKA}

Fauzi, Rizki.(2016). Survei Pola Pembinaan Ekstrakurikuler Olahraga Sepak Bola Sekolah di SMP Negeri di Kabupaten Kebumen

Pirman, Noperto.(2013). Minat Siswa Putra Dalam Mengikuti Ekstrakurikuler sepak Bola SMP Negeri 5 Parindu Kabupaten Sanggu

Ramadhan, Irsyad Faiz.(2018). Minat Siswa Dalam Mengikuti Ekstrakurikuler Olahraga di SMP Negeri 2 Berbah 